\title{
Citizenship ACT (591) OF GHANA AS A LogiC THEOREM AND ITS SEMANTIC IMPLICATIONS
}

\author{
NakpihIreneous Callistus \\ ${ }^{1}$ Department of Mathematics and Computing, St. John Bosco’s College of Education, \\ Navrongo, Ghana
}

\begin{abstract}
This paper presents excerpts of the natural text of the Citizenship Act of the Republic of Ghana, ACT 2000 (591), as a logic theorem in First Order Logic (FOL) language. The formalism of this piece of law is done to allow for semantic analysis of the text by machines. The results of this research also deals with the problem of ambiguities in the legal text, and reveals the semantic consequence of the natural construction or textual structure of the piece of law; one major problem of the semantics of legal text has been the problem of ambiguities, which largely affects interpretations that are alluded to legal statements. Some constructed sentences sometimes do not reflect the semantic intentions of the composers of the sentences, due to inherent ambiguities or technical faults in the structure of some parts of the statements. The formalism of the Act in this paper provides logical proofs and deductions which are asserted to establish clarity and to reveal semantic errors, or otherwise preserve the semantic intentions of the Act.
\end{abstract}

\section{KEYWORDS}

Natural Language Processing, Formalism, Logic Theorem, Semantic Analysis, Legal text.

\section{INTRODUCTION}

One of the major challenges in the legal practice is the complexity of expressions of legal language. Our legal world today is faced with two dimensions of this problem; on one hand they are faced with the ambiguous use of language and terminologies in legal text that makes it difficult for comprehension, which sometimes results into the making of fallacious conclusions which may occur in a claim made, facts established, arguments of lawyers or the decisions of a judges [1],[2]. On the other hand, they are faced with the complex nature of ambiguities itself which makes it difficult to identify them when they occur, which for some reason may be genuine or deliberate [3], or simply elusive [4],[5]. This problem presents different levels of difficulties for deductive reasoning through legal text for prices decision making.

Legal discourse as done in courts and senate houses have shown that, assessing the logical implications of legal statements can be a painful exercise and complex to keep track with the logical connections through all aspects of legal text in application [6]. This is because the natural expressions of legal text does not make its logical implication apparent just by reading the text; the use of words, concepts, and judgments is done in almost a codified manner that rather makes understanding of legal text a challenge through natural or simple processes [7]. This problem has resulted in some researchers suggesting that, legal text should be composed in what they term as Plain English [8],[9] whiles others have formulated new writing mechanics for drafting legal text [10], which they believe would avoid ambiguity and provide comprehensibility to legal text.

Language expressed in any natural form however, will require a system that would explain its fuzzy aspects and provide understanding to its logical semantics. The problem of semantics of natural language and information processing has always existed as a natural occurrence in human

DOI: $10.5121 /$ ijnlc. 2018.7502 
communication system. The natural form of expressing human thought and presentation of information at the best of our reasoning happens with some variances in semantics [11]. One statement could be expressed to have several meanings, while several statements could also be expressed to mean the same thing. This in essence reveals the beauty and creativity in natural language expression, and is not a challenge in human communications by itself, especially in ordinary communication of life. It is however challenging when other human activities depend on the right intended meaning of expressed statements, as in the law courts and senate houses.

Much as semantics of natural language can be very tricky, legal expressions presents more difficult situations, not only in the way it is being expressed, but also in the semantics ascribed to expressions made [12]. Legal statements as a matter of fact, are difficult to read, and also difficult to understand, and this is partly because legal statements are constructed with words which are mostly not familiar in common language expressions. Even practitioners in the domain sometimes allude different understanding to the same expressed statements in the legal field, and subject the statements to various argumentation to arrive at decisions [13]. This does not however suggest that legal statements do not have definite meanings and are therefore open to all kinds of interpretations. The rules that govern the interpretation of legal statement is quite clear in legal practice; what remains challenging is the problem of inherent ambiguities, incomprehensibility and lack of clarity in legal text, due to its form of presentation and fuzziness, and as a result poses the possibility of implying different meaning to the same legal statements [14], [15].

Natural Language Processing (NLP) is an aspect of Artificial Intelligence (AI) and computational linguistics that has sought to reconstruct language to close up semantic gaps, using computing tools[16]. NLP is a broad area that include aspects as different as, automatic translation, or knowledge acquisition from written or spoken texts. Natural Language Understanding as a branch of NLP attempts to translate natural language into a precise mathematical formalism in a way that will capture this informational essence of a text freed from the ambiguity and imprecision of human languages [17].

Various types of logic, from Description Logic [18] and Horn Logic [19] to First Order Logic [20], Monadic Second Order[21] and various types of non-monotonic logics [22] have been used as the target language in this translation process. When it comes to modelling the unconstrained human languages, all these approaches have had at best partial success in dealing with the problem of ambiguities in the semantics of language.

Legal language which is structured to preserve, to some extent, a pattern of logic reasoning, presents an opportunity to use logic as a model of it, with the purpose of reducing as much as possible, its residual ambiguities. Agreeably, there is a natural relation between logic and law [23], which has resulted in researchers focusing on the technical development of logic tools needed to model legal arguments adequately.

In this paper, we choose First Order Logic as a formal language to process a type of legal text, the Citizenship Act of Ghana, and thus present it as a logic system which reveals the logical consequences of the natural construction of legal statements, and as well provides a mechanism for deductive reasoning through the complex relations and logical connections of the all aspects of the text.

\section{LITERATURE SURVEY}

The quest to finding absolute means to sound reasoning through expressed natural language in any form that avoids fallacies, in order to establish lucid semantics of information is not unique to this research. This research evolved around questions logicians, argumentation theorist, linguistics, natural language processors, computer scientist and legal practitioners have asked 
over centuries up to date. Every domain of discipline has always sought some form of precision and clarity on how information is understood, presented and shared, with less effort. But the complexity of human language comes with this natural problem of ambiguity, which leaves researchers in a position of yet to absolutely bridge the semantic gap.

The idea to automate legal text and the use of computational tools in the law practice dates back to the 1940s. Some researchers conceived and expressed the idea of an automated information system for legal practice through Artificial Intelligence research. They indicated that, the correctness of justice and judgment depends on the mastery of facts and law; the challenge however remains in the quantity of legislative constructions, statutes, rulings, customs and practices, economic background and cases that may apply to facts of clients posed to lawyers engaged in a litigation. They also advanced their ideas to propose an automated legal research system called Lawdex, which was created based on punch card technology. The proposition of Lawdex was to be designed as an information retrieval system that leverages efforts to find laws needed for particular purposes[24].

Some researchers are of the opinion that, applying logic-based techniques and rule-based reasoning to law, could be a lot more helpful in the development of electronic system in the legal domain [25]. Logic-based techniques are by far one of the promising ways to deal with ambiguities in legal text. Anjali and Babu discussed the various types of ambiguities that occur in natural language and the need for computational tools to resolve them, acknowledging that this is one of the ways we can have clarity in the presentation of natural language [26]. Agreeably, research converges to the provision of logical tools for modelling legal language as the niche to the success of bridging the semantic gap in natural language. These ideas have been tested and a lot more tools have been built proving some level of success.

Even though computer scientists have proven to use logical tools for processing legal language, it still remains a debate among legal scholars as to whether logics exactly fits into legal reasoning and whether the role it plays has primary importance as stipulated by logicians and computer scientists. Some of these arguments led researchers to present a formal model of legal argumentation focusing on the reconciliation of symbolic logics and argumentation theories by reconstructing the fundamental pattern of legal reasoning and further implemented in Prolog programming language [27]. Sartor's model advanced the argument that one important necessity for the analysis and evaluation of legal arguments is formalism, which offers the possibilities of supporting them with some computing techniques. Real arguments could go through such evaluation to have its analysed results extended and checked by syntactic computation.

Legal formalism is a description of how legal decisions are supposed to be taken, drawing from logical structures to undisputable principles applied to facts. Formalism is noted to be a primary philosophy in decision-making processes in the legal domain, and yet remains to be a controversial issue among argumentation theorists, lawyers and other researchers.

We agree to some extent, the position of the legal scholars, on the difference between human reasoning and that of computers; reasoning by intuition and analogy as done by humans, and step by step algorithmic processes as done by computers are completely distinct. Computers at their best can perform some case-based reasoning as supervised or unsupervised learning which is nowhere close to the power and complexity of intuitive reasoning by the human brain. However, we may not also be able to throw away the idea of using computational tools to achieve better results in the process of decision-making in legal argumentation. Even though we find the debate by legal scholars very healthy, we believe that the formalism of legal language should not be the point for contention, instead, the divergent ideas by legal scholars and logicians should be converged, and as a matter of fact, the two positions of opinion augment each other. The weakness of logic for legal reasoning presents the opportunities for assessing the structure of 
International Journal on Natural Language Computing (IJNLC) Vol.7, No.5, October 2018

legal language and constructing it to a form that allows for the use of logical tools; this brings us to formalism and modelling of legal argumentation [27] which is able to capture isomorphism to clarify the structure of legal reasoning.

\section{Citizenship Of Ghana}

There are several provisions by Ghanaian laws that give people access and outlines procedures needed to acquire citizenship of Ghana. However, "along with the Constitution of Ghana, the Citizenship Act (591) is the exhaustive law relating to citizenship in Ghana.".The Act consolidated amendments of other citizenship laws of Ghana, and provides for the determination and acquisition of Citizenship of Ghana [28].

There are other relevant laws in addition to the nationality law which have effect on the access to Ghanaian nationality; Registration of Births and Deaths Act, 1965, National Identity Register Act, 2008, Immigration Act, 2003, the Ghana Refugee Law, 1992. All these laws have established in detail, how, when and where to attain different types of Ghanaian Citizenship (United Nations High Commissioner for Refugees [29], [30].

The Citizenship Act (591) consolidates and categorises the various types of Ghanaian citizenship into four parts. The first part describes existing citizenship by birth, which has been described by different constitutions at and for different periods of time or date, which are not in contraventions of each other. They are however put together in the Act (591) to establish all the conditions that are valid to ascertain citizenship of Ghana depending on the time period a person was born.

The second part of the Act defines the acquisition of Ghanaian Citizenship other than by birth. The laws of Ghana allows person of other nationalities to register to be citizen of Ghana or naturalise as Ghanaians. The Act provides the various conditions a person has to satisfy to obtain this type of citizenship of Ghana.

The third part of the Act is represented with three sections, that is, dual citizenship, renunciation of citizenship and deprivation of citizenship. The last part of the Act outlines miscellaneous provisions of the Act. This provides for all types of persons under different legal and natural condition to be able to have access to Ghanaian citizenship.

The access to Ghanaian citizenship or nationality, and the proof of nationality are impacted by institutions such as the Ministry of the Interior, Ghana Immigration Service, Ghana Refugee Board Ministry of Foreign Affairs and Rational Integration, National Identification Authority, Births and Deaths Registry, and the Ministry of Local Government and Rural Development [30], [31].

\section{RESUlts AND DiscuSSION}

The modelled text of the Citizenship Act (591) of Ghana in this paper, is done to provide a mechanism for analysing the semantics of the natural text of the Act. The logic model reveals the difference in the semantic consequence on the choice and use of words between their natural and logic form. The logic model of the text establishes a pattern of reasoning through the text, contrasting all other possible wrong meaning that could be ascribed to the text either accidentally or deliberately, due to the ambiguous use of some words in the text.

The text of the Act is constructed with logical connectives such as, if...then, or, and, and so forth. It is important to note that, as a general rule, the literal meaning of these logical connectives in natural language is always maintained in all logical use. The analysis made in this paper, reveals 
International Journal on Natural Language Computing (IJNLC) Vol.7, No.5, October 2018

the level of consistency between the semantics of the natural use of the logical connectives in the Act, and their semantic implications in the logic model of the text.

\subsection{Formalised TeXt Of The ACT}

We establish in this paper, that, the textual construction of the Act presents some level of inherent ambiguities in its semantics. The use of some words in the internal structure of the statements presents different meaning in their logical consequence. This kind of confusion does not seem to be apparent in the natural use of the words. The logical consequence of the use of some words or the style of sentence structure is only made picturesque in the formal model of the text.

Clarity of statements allows for comprehensibility and sound reasoning. If a statement is comprehensible, it reduces the possibility of wrong conclusions to be derived from it. The statements in the citizenship Act takes the form of antecedents and consequents; a structure that allows for deductive reasoning. The formalised text in this paper is therefore done to preserve clarity and comprehensibility of the text, and as well presents the text in a logic structure that allows for deductive reasoning.

The logic formalism allows us to move through the propositions, systematically assessing the truth state of each axiom during the process of reasoning in order to establish the semantics of the whole statement. All consequents of the statements in the Act are derived from their antecedents by means of the material implication, per the use of if..then conditionals in the Act. The statements in the Act as well follow the semantic pattern of $\Gamma \vDash A$, thus, for all set of premise that makes $\Gamma$ true, or that deduces $\Gamma$, also necessarily makes $A$ true or deduces $A$, and it is therefore impossible for a set of premise to be true and the semantic consequent to be false. This pattern is enforced and maintained in the formalised text. If all necessary conditions for an argument is established to be true then, its derived conclusion must be true.

\subsubsection{CONTINUATION OF EXISTING CITIZENSHIP}

The Section 1 of the Citizenship Act of Ghana states that "Every person who on the coming into force of the Constitution was a citizen of Ghana by law shall continue to be a citizen of Ghana."

Model:

$\exists \mathrm{lw}, \mathrm{gh}, \mathrm{T} \_$eoc law $(\mathrm{lw}) \wedge$ country $(\mathrm{gh}) \wedge$ time $\left(\mathrm{T} \_\right.$eoc $) \wedge$ at $\left(\mathrm{by}(\operatorname{existing}(\mathrm{Ctz}(\mathrm{x}, \mathrm{gh})), \mathrm{lw}), \mathrm{T} \_\right.$eoc $)$

$\forall \mathrm{xcont}(\mathrm{Ctz}(\mathrm{x}, \mathrm{gh})) \leftrightarrow \operatorname{at}\left(\mathrm{by}(\operatorname{existing}(\mathrm{Ctz}(\mathrm{x}, \mathrm{gh})), \mathrm{lw}), \mathrm{T} \_\right.$eoc $)$

In this model we have defined for any person $x$ who has continuous, cont, citizenship of Ghana, $g h ; x$ should necessarily have had an existing citizenship of Ghana by law by(existing $(\operatorname{Ctz}(x, g h)), l w)$, at the time of the enforcement of the constitution, T_eoc. This model also connotes that, if a person has an existing citizenship of Ghana by law at the time of the enforcement of the constitution, then the person can have continuous citizenship of Ghana.

The main challenge of the textual structure of the Section 1 of the Act is that, the statement is presented in a long non-punctuated sentence, which makes it difficult for readers to determine the scope of application of some of the entities in the text.

It is important to note that, the statements in the Act are declarative sentences and therefore holds truth-values, and the consequents of the statements depend on the true meaning of the antecedents, and not how it is being interpreted by readers, even though it is possible for an unguided reader to infer any possible meaning to them. 
International Journal on Natural Language Computing (IJNLC) Vol.7, No.5, October 2018

There are several possible ways the Section 1could be contemplated, per the structure of the sentence in the Act depending on how readers brake down the statement. We have placed shefferstrokes in the statement to make other ways of reading and reason through the text clearer.

Reasoning 1: Every person who on the coming into force of the Constitution was a citizen of Ghana by law I shall continue to be a citizen of Ghana.

Reasoning 2: Every person who on the coming into force of the Constitution was a citizen of Ghana by law I shall continue to be a citizen of Ghana.

Reasoning 3: Every person who on the coming into force of the Constitution was a citizen of Ghana I by law shall continue to be a citizen of Ghana.

In the Reasoning one, every person in the universe was already a Citizen of Ghana by law, at the time the constitution came into force. This way of reasoning through the statement presents citizenship at a time $t$ for every person $x$, and hence would produce the following model; $\forall x$ person $(x) \rightarrow \exists t$ time $(t) \wedge \operatorname{at}(C t z(x, g h), t)$.

However this is not the intent of the statement of the Act. Persons who already had Citizenship of Ghana at the time the constitution came into force, are the persons being referred to, and not just every person in the universe being citizen of Ghana at that particular time $t$. The model for this statement however preserves its intended meaning, by presenting the statement as an atomic proposition with defined arguments, which clarifies that all $x$ being referred to are specific $x$ that have citizenship of Ghana by law, at time $T_{-} e o c$, and these persons $x$ are being referred to as persons with existing citizenship, and only such persons can have continuous citizenship.

The text is also model to give a binding of the universal quantifier on persons $x$ a narrow scope with respect to the binding of the existential quantifier on the time and law entities; $\exists T \_e o c, l w$ having a wider scope over $\forall x$ emphasises that, persons $x$ can only have continuous citizenship at the time $T_{-} e o c$, which is a necessary condition for continuous citizenship. If the model had presented $\forall x$ to have a wider scope over $\exists T \_e o c, l w$, that would have meant that, for every person $x$ there exists a time $T_{-} e o c$ and a law $l w$ by which he or she can become citizen. This scopal ambiguity is however resolved by the structure of model that is presented here.

The application of the term by law in the statement presents two different meanings the statement in reasoning two and three, depending on how the term is applied or connected to the rest of the sentence. The reasoning two suggests that, the persons were citizens of Ghana by law, while the second suggests that, the persons were citizens of Ghana, but shall now continue to be citizens by law. These two presentations of the same statement do not essentially carry the same meaning. The application of the law shifts the whole meaning and intention of the statement.

The right model $\forall x$ at $\left(\right.$ by $($ existing $\left.(C t z(x, g h)), l w), T \_e o c\right) \leftrightarrow \operatorname{cont}(C t z(x, g h))$, however, is constructed to enforce the application of every concept to objects in the statement by means of defined predicates and their arguments. The axiom by(existing $(C t z(x, g h)), l w)$, clarifies that, at time $T_{-} e o c, x$ must be a citizen of Ghana by law in order to have continues citizenship.

We also establish that, formalism of the Section 1of the Act with a material implication may not work well for some instance of its deductive reasoning. We assert the validity of the model per the rules of material implication, the following is thus established;

- if a person satisfies at (by (existing $\left.(C t z(x, g h)), l w), T \_e o c\right)$, and such a person necessarily satisfies $\operatorname{cont}(\operatorname{Ctz}(x, g h))$ as well, then the argument $\forall x$ at $\left(b y(\right.$ existing $\left.(C t z(x, g h)), l w), T_{\_} e o c\right) \rightarrow \operatorname{cont}(C t z(x, g h))$ is valid. 
- If a person does not satisfy at(by(existing $\left.(C t z(x, g h)), l w), T \_e o c\right)$, and as well does not satisfy $\operatorname{cont}(\operatorname{Ctz}(x, g h))$, then, the argument is still valid.

- However, if a person does not satisfy at(by(existing $\left.(C t z(x, g h)), l w), T \_e o c\right)$, but satisfies $\operatorname{cont}(\mathrm{Ctz}(x, g h))$, the argument will still remain valid; this is because, at (by(existing $(\mathrm{Ctz}(x$, $\left.g h)),(w), T_{-} e o c\right)$ should not be the only proposition that should deduce $\operatorname{cont}(\mathrm{Ctz}(x, g h))$ according to the material conditional deduction rules. There should be other propositions that should deduce $\operatorname{cont}(\mathrm{Ctz}(x, g h))$.

The challenge of the material implication in last assertion above is that, the definition of continuous citizenship in the context of the Act is constructed to be a consequent of only persons who already had citizenship at the time the constitutions came into force, that is, existing citizenship. However, the text conditional provided in the Act does implements a unidirectional material implication, which does not enforce the intended deduction of $\operatorname{cont}(\operatorname{Ctz}(x, g h))$ to be based on only at(by(existing $\left.(C t z(x, g h)), l w), T \_e o c\right)$. So, even though the argument is valid for an instance where $x$ does not satisfy at(by(existing $\left.(C t z(x, g h)), l w), T_{-} e o c\right)$ but satisfies $\operatorname{cont}(\operatorname{Ctz}(x$, $g h)$ ), changes the semantics consequence in the context of the Act. Emphatically, Persons who did not have existing citizenship by law, at the time the constitution came into force, cannot have continuous citizenship, and therefore should not be valid in the context of the Act as well as the logical formalism.

We therefore denote that, a material bi-conditional implication resolves this problem (which is not the way the statement was constructed in the Act), and maintains the semantics of the intent of the Act, thus;

$\operatorname{cont}(C t z(x, g h)) \leftrightarrow \operatorname{at}\left(b y(\right.$ existing $\left.(C t z(x, g h)), l w), T \_e o c\right)$.

This is to say that, a person can have continuous citizenship, if and only if such a person satisfies at $\left(b y(\right.$ existing $\left.(C t z(x, g h)), l w), T \_e o c\right)$.

Therefore;

$\operatorname{cont}(C t z(x, g h)) \rightarrow \operatorname{at}\left(b y(\right.$ existing $\left.(C t z(x, g h)), l w), T_{-} e o c\right)$ and

$\operatorname{at}\left(\operatorname{by}(\operatorname{existing}(\mathrm{Ctz}(x, \mathrm{gh})), l w), T_{-} e o c\right) \rightarrow \operatorname{cont}(\mathrm{Ctz}(x, g h))$.

The antecedent at(by(existing $\left.(\operatorname{Ctz}(x, g h)), l w), T \_e o c\right)$ therefore becomes a necessary and sufficient condition for a person to have continuous citizenship.

Based on the bi-conditional implication, the argument $\operatorname{cont}(\operatorname{Ctz}(x, g h)) \leftrightarrow \operatorname{at}(\operatorname{by}(\operatorname{existing}(\mathrm{Ctz}(x$, $\left.g h)),(w), T_{\_} e o c\right)$ is not valid for two instances elaborated in the validity check in the form $p \rightarrow q$ and $q \rightarrow p$. For;

P: $\operatorname{cont}(\mathrm{Ctz}(\mathrm{x}, \mathrm{gh})) \rightarrow$ at $\left(\right.$ by $($ existing $(\mathrm{Ctz}(\mathrm{x}, \mathrm{gh})), \mathrm{lw}), \mathrm{T} \_$eoc $)$

q: at (by(existing $\left.(\operatorname{Ctz}(x, g h)), 1 w), T \_e o c\right) \rightarrow \operatorname{cont}(\operatorname{Ctz}(x, g h))$ 


$$
\text { Therefore; } \frac{\neg \operatorname{cont}(\mathrm{Ctz}(\mathrm{x}, \mathrm{gh}))}{\frac{\neg \mathrm{P}}{\mathrm{q}}}
$$$$
\text { and } \frac{p}{-q}
$$

Therefore;

$$
\operatorname{cont}(\mathrm{Ctz}(\mathrm{x}, \mathrm{gh}))
$$$$
\left.\neg \text { at (by (existing }(\mathrm{Ctz}(\mathrm{x}, \mathrm{gh})), 1 \mathrm{w}), \mathrm{T}_{-} \text {eoc }\right)
$$

For every instance of $x$, at (by (existing $\left.(C t z(x, g h)), l w), T \_e o c\right)$ is necessary for cont $(C t z(x, g h))$, and $\operatorname{cont}(C t z(x, g h))$ is sufficient for $\operatorname{at}\left(\operatorname{by}(\operatorname{existing}(C t z(x, g h)), l w), T_{-} e o c\right)$. This satisfies the intended semantic consequence of the natural statement in the citizenship Act. The logic structure here emphasis that, a person must have existing citizenship before he or she can acquire continuous citizenship of Ghana. This condition is however not made firm by the structure of natural expression of the text in the Act. The logical implication expressed in the text of the Act (which is an unintended outcome or misrepresentation by the use of textual implication) allows for a person to have continuous citizenship without necessarily having an existing citizenship of Ghana. The Act in converse seeks to establish that the, there are no other means of having continuous citizenship except for the condition of having existing citizenship, which unfortunately was misrepresented by the choice and use of material implication in the text.

One of the important factors that determine the semantics of a statement, is the entities in the statements and how they relate with each other in the sentence structure. The true meaning of a statement can be easily thrown off if the intended relations of the objects in the internal structure of the statements are misplaced or misinterpreted. The literal intended meaning of statements of the Act as well as their legal implications can be easily misinterpreted if a reader is not guided, since that is one of the generic problems of natural language.

A logical construction of the statements in the Act required that, entities in the statements are clearly identified, as well as establish how these entities relate. This can be very challenging, because, some words are implied differently in the Act from their generic or lateral usage, which creates the problem of ambiguities in the Act. We therefore establish through this model, that, a material implication will not work for this piece of law when asserted logically. A bi-conditional implication however provides adequate logical intention for the Section 1of the Act.

\subsubsection{PERSONS BORN BEFORE 6/3/57}

The Section 3 of the Act describes a citizenship type defined for persons born before the independence of Ghana. This citizenship type is not based on any known law preceding the independence of Ghana. It is however a citizenship by birth obtained by decent which is also a legal means of attaining citizenship in Ghana even though we do not have any conditions defining citizenship by decent in the Act.

According to the Act, there exists a time $t$ which is the date of the independence of Ghana, such that every person $x$ born before that time $\operatorname{born}(x$, before $(t))$ is citizen of Ghana by birth $\operatorname{byBirth}(\operatorname{Ctz}(x, g h))$, but on the basis that the person should be born in Ghana $\operatorname{born}(x, \operatorname{in}(g h))$, and at least one of his parents was born in Ghana $\operatorname{born}(p, \operatorname{in}(g h))$, or grandparent was born in Ghana $\operatorname{born}(g p, \operatorname{in}(g h))$. The use of $p$ for parent provides a variable for either mother or father, thus, $\operatorname{parent}(p, x) \rightarrow \operatorname{father}(p, x)$ V mother $(p, x)$. The same is done with the use of $g p$ as a variable for 
any of the grandparents of $x$ who is a parent of $p, \operatorname{grandparent}(g p, x) \rightarrow \operatorname{parent}(p, x) \wedge \operatorname{parent}(p g$, $p$ ). The model is as follows;

$\exists \mathrm{t}, \mathrm{x}$ time $(\mathrm{t}) \wedge$ person $(\mathrm{x}) \wedge \operatorname{time}(\mathrm{t})=03.06 .57 \wedge \operatorname{born}(\mathrm{x}$, before $(\mathrm{t}))$

father(p, $\mathrm{x}) \vee \operatorname{mother}(\mathrm{p}, \mathrm{x})$

$\operatorname{parent}(\mathrm{p}, \mathrm{x}) \rightarrow$ father(p, $\mathrm{x}) \vee$ mother(p, x)

grandparent $(g p, x) \rightarrow \operatorname{parent}(p, x) \wedge \operatorname{parent}(g p, p)$

$\exists \mathrm{p} \operatorname{parent}(\mathrm{p}, \mathrm{x}) \wedge \operatorname{born}(\mathrm{p}$, in $(\mathrm{gh}))$

$\exists$ gpgrandparent $(g p, x) \wedge$ born $(g p$, in $(g h))$

$\exists \mathrm{t}, \mathrm{p}, \mathrm{gp}$ time $(\mathrm{t})=03.06 .57 \wedge \operatorname{born}(\mathrm{x}, \mathrm{in}(\mathrm{gh})) \wedge \operatorname{born}(\mathrm{x}$, before $(\mathrm{t})) \wedge \operatorname{parent}(\mathrm{p}, \mathrm{x}) \wedge$ grandparent $(\mathrm{gp}$, $\mathrm{x}) \wedge[\operatorname{born}(\mathrm{p}, \operatorname{in}(\mathrm{gh})) \vee \operatorname{born}(\mathrm{gp}, \operatorname{in}(\mathrm{gh}))] \rightarrow \operatorname{byBirth}(\mathrm{Ctz}(\mathrm{x}, \mathrm{gh}))$

$\exists \mathrm{p}, \operatorname{parent}(\mathrm{p}, \mathrm{x}) \wedge \neg \operatorname{born}(\mathrm{x}, \operatorname{in}(\mathrm{gh})) \wedge \operatorname{born}(\mathrm{p}, \operatorname{in}(\mathrm{gh})) \rightarrow \operatorname{byBirth}(\mathrm{Ctz}(\mathrm{x}, \mathrm{gh}))$

Again we come across a very trick sentence structure in the Act that is open ended. In both subsections, the model revealed that, the citizenship of any arbitrary $x$ is dependent on only the birth places of the parent or grandparent as external factors, and thus, $\operatorname{born}(p, \operatorname{in}(g h)) V \operatorname{born}(g p$, in $(g h))$. Person $x$ per these conditions derives citizenship from $p$ and $g p$. The tricky aspect is that the citizenship state of $p$ and $g p$ is not known within this piece of law.

The possible interpretations which introduces the twist to the semantics of this section is that, if the condition $\operatorname{born}(p, \operatorname{in}(g h)) V \operatorname{born}(g p$, $\operatorname{in}(g h))$ is satisfied, and $p$ and $g p$ do not have citizenship of Ghana, $x$ will still qualify to be citizen of Ghana as implied by this Section of the Act. However, this may not work even for the literal inference for having citizenship of Ghana. That is because, parents of $x$ not being Ghanaian, irrespective of their citizenship, may as well mean that such parents, through whom $x$ drives citizenship from, may not originally be Ghanaians by birth.

If another variable $y$ is introduced satisfying all the conditions of this Section 3 as child of $x$ whose citizenship is yet to be determined. Such a $y$ will still qualify to be citizen of Ghana as long as the birth place of $x$ is Ghana, and this should not be the case even though that is how it is being per the text of the Act. The model below is done to support the argument we have advanced on Section 3 so far;

$\operatorname{parent}(\mathrm{x}, \mathrm{y})$

grandparent(gp, $\mathrm{x})$

$\exists \mathrm{t}, \forall \mathrm{y}$ time $(\mathrm{t}) \wedge$ person $(\mathrm{y}) \wedge \operatorname{time}(\mathrm{t})=03.06 .57 \wedge$

$\operatorname{born}(\mathrm{y}, \operatorname{before}(\mathrm{t}))$

$\exists$ gpgrandparent $(\mathrm{gp}, \mathrm{y}) \wedge$ born $(\mathrm{gp}, \mathrm{in}(\mathrm{gh}))$

$\exists \mathrm{t}, \mathrm{p}, \operatorname{gptime}(\mathrm{t})=03.06 .57 \wedge \operatorname{born}(\mathrm{y}, \operatorname{in}(\mathrm{gh})) \wedge \operatorname{born}(\mathrm{y}, \operatorname{before}(\mathrm{t})) \wedge \operatorname{parent}(\mathrm{x}, \mathrm{y}) \rightarrow \operatorname{byBirth}(\mathrm{Ctz}(\mathrm{y}$, gh))

In the model above, $y$ derives citizenship from $x$ who has already been defined in the previous model as a person born in Ghana. By definition of the law, this is sufficient for $y$ to be citizen of Ghana, even though the citizenship of $x$ is yet to be asserted. This presents a problem of inherent fallacy in this Section of the law. That is because, it presents a situation of affirming a person to be citizen by birth whose parents may not have citizenship of Ghana, which defies some rules of obtaining citizen of Ghana.

The semantics of the natural presentation of this text can be resolved, if the relationship established by the law between the antecedent and the consequent is more of causal relationship than a logical deductive relationship. By this, we can say that, $\operatorname{born}(p, \operatorname{in}(g h)) V \operatorname{born}(g p, \operatorname{in}(g h))$ is part of the system that causes $x$ to be citizen of Ghana by birth, since it is considered relevant by the constitution. This makes this type of citizenship of Ghana an empirical event other than a logic condition. 
The causal effect relationship in this piece of law rest on some qualitative theoretical assumptions; the assumption that parents or grandparents of persons born in Ghana before the independence of Ghana have citizenship of Ghana by decent. Even though stating this as an axiom in a logical proposition works well, the possibilities of occurrences of such persons not being Ghanaians will always result in a logical fallacy which is undesirable for any logic system. The probabilistic cause of a parent or a grandparent born in Ghana but not Ghanaian will result into $x$ not being Ghanaian as well. As solution to the preserve the intended semantics in the Act, this study presents the consequents of Section 3 of the Act as a causal effect of the antecedent other than as logical effect. Thus;

$\mathrm{P}(\neg \mathrm{Ctz}(\mathrm{x}, \mathrm{gh}) \mid \neg[\mathrm{Ctz}(\mathrm{p}, \mathrm{gh}) \vee \mathrm{Ctz}(\mathrm{gp}, \mathrm{gh})])$.

\subsubsection{Persons Born ON OR AFTER 6/3/57 BUt Before 22/8/69}

The type citizenship by birth defined in the Section 4of the Actwas enforced by the first parliamentary elections in Ghana, where we have two time periods that generally defines it; a person $x$, born on or after $6^{\text {th }}$ March 1957which is the independence date of Ghana which we call $t 1$, thus, $\operatorname{born}\left(x, \operatorname{on}(t 1) V \operatorname{born}(x, \operatorname{after}(t 1))\right.$, and before $22^{\text {nd }}$ August 1969 which we call $t 2$, thus, $\operatorname{born}(x$, before(t2)), qualifies to be citizen of Ghana by birth, if $x$ was born in or outside Ghana; this general qualifying criteria also depends on the birth place and citizenship status of the parents, grandparents and/or great grandparents of $x$, all these criteria are asserted together to determine this type of citizenship for $x$.

What is interesting in this part of the Act as a results of the logic model is that, the natural use of the or disjunction implies that; $x$ can be born on $t 1$ only, $\operatorname{born}(x$, on(t1)), or $x$ can be born after tlonly,born $(x$, after(t1)), or, $x$ can be born on $t 1$ and after $t 1$ at the same time . However, it is not possible in real sense for a person to be born on two different dates, as implied by the inclusive use of the or disjunction in the statement. The use of either in the text would have enforced an exclusionary application of the disjunction to maintain the intended logical semantics of the statement. This study enforces the semantic intention of the statement, by the use of the exclusive disjunction, which takes out the possibility of the occurrence of $\operatorname{born}(x, \operatorname{on}(t 1))$ and $\operatorname{born}(x$, after(t1)) at the same time. The statement is therefore modelled as follows;

$\exists \mathrm{t} 1, \mathrm{t} 2 \mathrm{time}(\mathrm{t} 1)=03.06 .57 \wedge$ time $(\mathrm{t} 2)=22.08 .69$

$\forall \mathrm{x}$ born $(\mathrm{x}$, on $(\mathrm{t} 1) \oplus \operatorname{born}(\mathrm{x}$, after $(\mathrm{t} 1)) \wedge$ born $(\mathrm{x}$, before $(\mathrm{t} 2))$

A person defined by the model above can be citizen of Ghana by birth if he or she satisfies either of the two conditions in Section 4(1) of the Act. Section 4(1)(a) is specified for persons born in or outside Ghana; the law requires that either of the parents of the person should be born in Ghana, and at least a grandparent or great grandparent of the person should be born in Ghana.

Here again, the exclusive use of the disjunction either (used in the Act) for the parents of $x$ being born in Ghana, puts a twists on some parts of the semantics in the statement; either of the parents of person $x$ would mean that, either the mother or the father of $x$, and not both of them being born in Ghana. By extension, $x$ qualifies for citizenship of Ghana, if, only the mother of $x$ was born in Ghana, or if, only the father of $x$ was born in Ghana. Person $x$ however, is not qualified if both mother and father are born in Ghana, according to the exclusionary use of the disjunctive either as naturally expressed in the Act. This however, does not conform to the common sense of the law. The inclusive use of the disjunction or in $\operatorname{born}([\operatorname{father}(p, x)$ V mother $(p, x)]$, in $(g h))$, will rather maintain the intended semantics of the statement. The inclusive use of the disjunction, would imply that, both mother and father born in Ghana does not violate the ascertaining of citizenship by person $x$. The model is as follows;

Persons born in Ghana: 
father(p, x) $\vee$ mother(p, $x)$

parent $(\mathrm{p}, \mathrm{x}) \rightarrow$ father $(\mathrm{p}, \mathrm{x}) \vee$ mother(p, $\mathrm{x})$

grandparent $(g p, x) \rightarrow \operatorname{parent}(p, x) \wedge \operatorname{parent}(g p, p)$

greatgrandparent (ggp, $\mathrm{x}) \rightarrow \operatorname{grandparent}(\mathrm{gp}, \mathrm{x}) \wedge$ parent(ggp, gp)

Therefore;

$\exists x, p, g p, g g p$

$\operatorname{parent}(\mathrm{p}, \mathrm{x}) \wedge \operatorname{grandparent}(\mathrm{gp}, \mathrm{x}) \wedge \operatorname{greatgparent}(\mathrm{ggp}, \mathrm{x}) \wedge \operatorname{born}(\mathrm{x}, \operatorname{in}(\mathrm{gh})) \wedge \operatorname{born}([\operatorname{father}(\mathrm{p}, \mathrm{x}) \vee$ $\operatorname{mother}(\mathrm{p}, \mathrm{x})], \operatorname{in}(\mathrm{gh})) \wedge[\operatorname{born}(\mathrm{gp}, \operatorname{in}(\mathrm{gh})) \vee \operatorname{born}(\mathrm{ggp}, \operatorname{in}(\mathrm{gh}))]$

Persons born outside Ghana:

$\exists x, p, g p, g g p$

$\operatorname{parent}(\mathrm{p}, \mathrm{x}) \wedge \operatorname{grandparent}(\mathrm{gp}, \mathrm{x}) \wedge \operatorname{greatgparent}(\operatorname{ggp}, \mathrm{x}) \wedge \neg \operatorname{born}(\mathrm{x}, \operatorname{in}(\mathrm{gh})) \wedge \operatorname{born}(\mathrm{p}, \operatorname{in}(\mathrm{gh})) \wedge$ [born(gp, in (gh)) $\vee$ born(ggp, in(gh))]

Therefore;

$\forall \mathrm{x}[\operatorname{born}(\mathrm{x}, \operatorname{in}(\mathrm{gh})) \oplus \neg \operatorname{born}(\mathrm{x}, \operatorname{in}(\mathrm{gh}))] \wedge[\operatorname{born}(\mathrm{x}, \operatorname{on}(\mathrm{t} 1) \oplus \operatorname{born}(\mathrm{x}, \operatorname{after}(\mathrm{t} 1))] \wedge \operatorname{born}(\mathrm{x}$, before(t2))] $\rightarrow \exists \mathrm{p}, \quad g p, \quad g g p \operatorname{parent}(\mathrm{p}, \mathrm{x}) \wedge \operatorname{grandparent}(\mathrm{gp}, \mathrm{x}) \wedge \operatorname{greatgparent}(\mathrm{ggp}, \mathrm{x}) \wedge$ $\operatorname{born}([$ father(p, x $) \vee \operatorname{mother}(\mathrm{p}, \mathrm{x})], \operatorname{in}(\mathrm{gh})) \wedge[\operatorname{born}(\mathrm{gp}, \operatorname{in}(\mathrm{gh})) \vee \operatorname{born}(\mathrm{ggp}, \operatorname{in}(\mathrm{gh}))] \rightarrow$ $\operatorname{byBirth}(\mathrm{Ctz}(\mathrm{x}, \mathrm{gh}))$

$\forall \mathrm{x}, \exists \mathrm{p}, \operatorname{gp} \operatorname{born}(\mathrm{x}, \operatorname{in}(\mathrm{gh})) \wedge \operatorname{parent}(\mathrm{p}, \mathrm{x}) \wedge \neg \operatorname{born}(\mathrm{p}, \operatorname{in}(\mathrm{gh})) \wedge \operatorname{grandparent}(\mathrm{gp}, \mathrm{x}) \wedge \operatorname{born}(\mathrm{gp}$, $\operatorname{in}(\mathrm{gh})) \rightarrow \operatorname{byBirth}(\mathrm{Ctz}(\mathrm{x}, \mathrm{gh}))$

The Section 4(2) of the Act defines person $x$ to claim its citizenship through a parent, claimedThrough(Ctz(x,gh), p), a grandparent, claimedThrough( $C t z(x, g h), g p)$, or great grandparent claimedThrough $(C t z(x, g h), g g p)$. The law emphasises that, if $p$ or $g p$ or $g g p$ through whom $x$ claims citizenship lose their citizenship at the time of birth of $x, x$ will in effect not be citizen of Ghana by birth.

$\exists p$, gp, ggp

$\operatorname{parent}(\mathrm{p}, \mathrm{x}) \wedge \operatorname{grandparent}(\mathrm{gp}, \mathrm{x}) \wedge \operatorname{greatgparent}(\mathrm{ggp}, \mathrm{x}) \wedge$ [claimedThrough( $\mathrm{Ctz}(\mathrm{x}, \mathrm{gh}), \mathrm{p})$ VclaimedThrough( $\mathrm{Ctz}(\mathrm{x}, \mathrm{gh}), \mathrm{gp})$ VclaimedThrough( $\mathrm{Ctz}(\mathrm{x}, \mathrm{gh}), \operatorname{ggp})] \wedge[\mathrm{at}(\neg \mathrm{Ctz}(\mathrm{p}, \mathrm{gh})$, $\operatorname{birth}(\mathrm{x})) \wedge$ at $(\neg \mathrm{Ctz}(\mathrm{gp}, \mathrm{gh}), \operatorname{birth}(\mathrm{x})) \wedge$ at $(\neg \mathrm{Ctz}(\mathrm{ggp}, \mathrm{gh}), \operatorname{birth}(\mathrm{x}))] \rightarrow \neg \mathrm{Ctz}(\mathrm{x}, \mathrm{gh})$

The Section 4(3) of the Act also emphasises the importance of $p$ and $g p$ having citizenship of Ghana, and even the type of citizenship they must possess for $x$ to be able to claim citizenship through them, thus;

$\operatorname{by}(\operatorname{at}([\operatorname{Ctz}(\operatorname{father}(\mathrm{p}, \mathrm{x})) \vee \operatorname{Ctx}(\operatorname{mother}(\mathrm{p}, \mathrm{x}))], \operatorname{birth}(\mathrm{x})), \operatorname{registration}) \oplus \operatorname{by}(\operatorname{at}([\operatorname{Ctz}(\operatorname{father}(\mathrm{p}, \mathrm{x}))$

$\operatorname{vCtx}(\operatorname{mother}(\mathrm{p}, \mathrm{x}))]$, birth $(\mathrm{x}))$, naturalization).

The implication of the literal use of the disjunction in this section is problematic. A parent should have citizenship of Ghana either by registration or naturalisation and not both type of citizenship at the same time. The citizenship status of a parent that qualifies $x$ can be the father or mother, or both at same time. This is enforced by the right use of the disjunctive connectives in the model.

The Section 3(a) and 3(b) in the Act are the same but are separated as different conditions. The difference lies in the use of both for persons born outside Ghana in Section 3(b) in place of either for persons born in Ghana in Section 3(a). Hence, the first part of the statement is modeled as; 
$\exists \mathrm{t} 1, \mathrm{t} 2$ time $(\mathrm{t} 1) \wedge$ time $(\mathrm{t})=03.06 .57 \wedge$ time $(\mathrm{t} 2) \wedge$ time $(\mathrm{t} 2)=22.08 .69$

$\forall \mathrm{x} \operatorname{born}(\mathrm{x}, \mathrm{in}(\mathrm{gh})) \wedge[\operatorname{born}(\mathrm{x}, \operatorname{on}(\mathrm{t} 1) \oplus \operatorname{born}(\mathrm{x}, \operatorname{after}(\mathrm{t} 1))] \wedge \operatorname{born}(\mathrm{x}$, before (t2)) $\rightarrow \exists \mathrm{p}$ father(p, $\mathrm{x}) \vee \operatorname{mother}(\mathrm{p}, \mathrm{x}) \wedge \operatorname{by}(\operatorname{at}([\mathrm{Ctz}($ father(p,x $)) \vee \operatorname{Ctz}(\operatorname{mother}(\mathrm{p}, \mathrm{x}))]$, $\operatorname{birth}(\mathrm{x}))$, registration $) \oplus \operatorname{by}(\operatorname{at}([\operatorname{Ctz}(\operatorname{father}(\mathrm{p}, \mathrm{x})) \vee \operatorname{Ctz}(\operatorname{mother}(\mathrm{p}, \mathrm{x}))]$, birth $(\mathrm{x}))$, naturalization $) \rightarrow$ byBirth(Ctz(x, gh))

The use of both is to emphasise that, one parent alone, whether mother or father being born in Ghana does not form part of the qualifying criteria for persons born outside Ghana. Both parents at least should be born in Ghana. The use of both therefore will function as conjunctive connective in the statement.

$\exists \mathrm{t} 1, \mathrm{t} 2$ time $(\mathrm{t} 1) \wedge$ time $(\mathrm{t})=03.06 .57 \wedge$ time $(\mathrm{t} 2) \wedge$ time $(\mathrm{t} 2)=22.08 .69$

$\forall \mathrm{x} \operatorname{born}(\mathrm{x}, \operatorname{in}(\mathrm{gh})) \wedge[\operatorname{born}(\mathrm{x}, \operatorname{on}(\mathrm{t} 1) \vee \operatorname{born}(\mathrm{x}, \operatorname{after}(\mathrm{t} 1))] \wedge \operatorname{born}(\mathrm{x}$, before (t2)) $\rightarrow \exists \exists$ father(p, $x) \vee \operatorname{mother}(\mathrm{p}, \mathrm{x}) \wedge \operatorname{by}(\operatorname{at}([\operatorname{Ctz}($ father $(\mathrm{p}, \mathrm{x})) \wedge \mathrm{Ctz}(\operatorname{mother}(\mathrm{p}, \mathrm{x}))]$, $\operatorname{birth}(\mathrm{x}))$, registration $) \oplus \operatorname{by}(\operatorname{at}([\mathrm{Ctz}(\operatorname{father}(\mathrm{p}, \mathrm{x})) \wedge \mathrm{Ctz}(\operatorname{mother}(\mathrm{p}, \mathrm{x}))]$, birth $(\mathrm{x}))$, naturalization $) \rightarrow$ $\operatorname{byBirth}(\mathrm{Ctz}(\mathrm{x}, \mathrm{gh}))$

\subsubsection{Persons Born ON OR AfTer 22/8/69}

The Section 5of the Act is defined for persons born on or after the date of enforcement of the 1960 constitution of Ghana. It follows the same definition as the previous section, but with a new time stamp time $(t 3)=24.09 .79$, by which $x$ has to be born at $t 2$ in the previous section but before $t 3$. The parent $p$ is also defined to have citizenship of Ghana. However, $g p$ does not form part of the criteria for $x$ to claim citizenship, and this is because, $p$ being citizen of Ghana remains sufficient for $x$ to claim citizenship through $p$ without seeking to extend claim of citizenship through $g p$. The citizenship of $p$ however, should be valid at the time $x$ was born, otherwise, $x$ will not be able to claim citizenship through $p$. This emphasises the importance of Citizenship of $p$ or $g p$ having effect on the Citizenship of $x$, which is in converse description of ascertaining citizenship in the Section 3 of the Act. The model for the Section 3 of the Act is as follows;

$\exists \mathrm{t} 3 \mathrm{time}(\mathrm{t} 3)=24.09 .79$

$\forall \mathrm{x}[\operatorname{born}(\mathrm{x}, \operatorname{in}(\mathrm{gh})) \oplus \neg \operatorname{born}(\mathrm{x}, \operatorname{in}(\mathrm{gh}))] \wedge[\operatorname{born}(\mathrm{x}, \operatorname{on}(\mathrm{t} 2) \oplus \operatorname{born}(\mathrm{x}, \operatorname{after}(\mathrm{t} 2))] \wedge \operatorname{born}(\mathrm{x}$, before(t3))] $\rightarrow \exists \mathrm{p}$ parent $(\mathrm{p}, \mathrm{x}) \wedge[\operatorname{at}(\mathrm{Ctz}(\mathrm{p}, \mathrm{gh}), \operatorname{birth}(\mathrm{x}))] \rightarrow \operatorname{byBirth}(\mathrm{Ctz}(\mathrm{x}, \mathrm{gh}))$.

\subsubsection{PERSONS Born ON OR AFTER 24/9/79}

Section 6 of the Act implements citizenship defined from the 1979 constitution of Ghana. The citizenship of $x$ is also the same as that of Section 5 of the Act, but with a time stamp of $t 4$. Here again, the definition states explicitly that $p$ or $g p$ should have citizenship of Ghana as a criteria for $x$ to claim his or her citizenship through them.

$\exists \mathrm{x}, \mathrm{t} 4, \mathrm{p}, \mathrm{gp} \operatorname{born}(\mathrm{x}, \mathrm{in}(\mathrm{gh})) \wedge$ time $(\mathrm{t} 4)=07.01 .93$

$\wedge[\operatorname{born}(\mathrm{x}, \operatorname{on}(\mathrm{t} 3)) \oplus \operatorname{born}(\mathrm{x}, \operatorname{after}(\mathrm{t} 3))] \wedge \operatorname{born}(\mathrm{x}$, before $(\mathrm{t} 4))]$

$\wedge$ parent $(\mathrm{p}, \mathrm{x})$

$\wedge$ grandparent(gp, $\mathrm{x})$

$\wedge[$ at $(\operatorname{Ctz}(\operatorname{father}(\mathrm{p}, \mathrm{x})), \operatorname{birth}(\mathrm{x})) \vee$ at $(\operatorname{Ctz}(\operatorname{mother}(\mathrm{p}, \mathrm{x})), \operatorname{birth}(\mathrm{x}))]$

$\operatorname{VCtz}($ grandparent $(\mathrm{gp}, \mathrm{x}))$, $\operatorname{birth}(\mathrm{x}))$

Sections 6(b) is similar to 6(a), but $x$ can only claim citizenship through $p$ in 6(a).

$\exists \mathrm{x}, \mathrm{t} 4, \mathrm{p}, \mathrm{gp} \neg \operatorname{born}(\mathrm{x}, \mathrm{in}(\mathrm{gh})) \wedge$ time $(\mathrm{t} 4)=07.01 .93$

$\wedge[\operatorname{born}(\mathrm{x}$, on $(\mathrm{t} 3)) \oplus \operatorname{born}(\mathrm{x}, \operatorname{after}(\mathrm{t} 3))] \wedge \operatorname{born}(\mathrm{x}, \operatorname{before}(\mathrm{t} 4))]$

$\wedge$ parent $(\mathrm{p}, \mathrm{x})$

$\wedge[\operatorname{at}(\operatorname{Ctz}(\operatorname{father}(\mathrm{p}, \mathrm{x})), \operatorname{birth}(\mathrm{x})) \vee \operatorname{at}(\operatorname{Ctz}(\operatorname{mother}(\mathrm{p}, \mathrm{x})), \operatorname{birth}(\mathrm{x}))]$ 


\subsubsection{Persons Born ON OR AFTER 7/1/93}

The Section 7 of the Act provides that, a person is citizen of Ghana by birth if he or she is born on or after the stipulated date in the provision, and at the time of his birth either [emphasis added] of his parents was citizen of Ghana. Either of the parents of the person, to mean that, if only the mother of the person was citizen of Ghana, or, if only the father of the person was citizen of Ghana, but not both of them with citizenship of Ghana at the same time, according to the exclusive use of the disjunctive either.

The disjunctive either in the Section 7 just as in the other sections might have not been intended for its exclusive use, but it does however presents different logical consequence for the statements it connects, this is because (as elaborated in the other sections) the default literal and structural use either implies exclusivity.

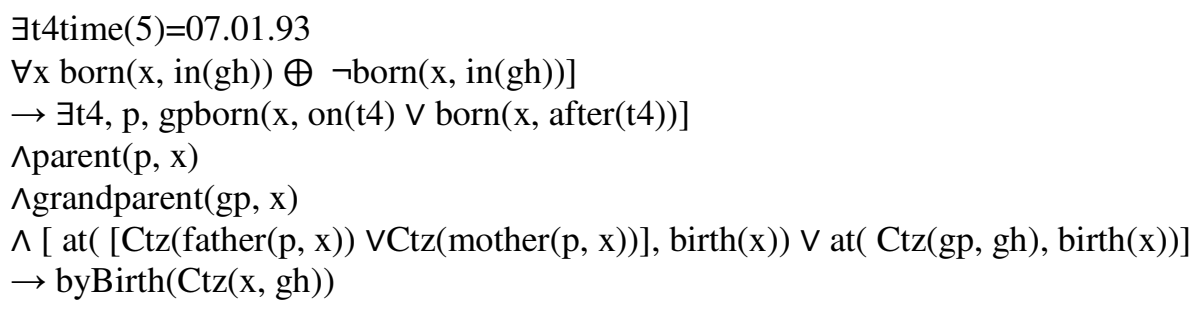

\subsubsection{FOUNDLINGS}

The Citizenship of a child $x$ whose is found in Ghana, found $(x, \operatorname{in}(g h))$ whose age is not more than seven years, age $(x)<8$, and whose parents are unknown $\neg \operatorname{known}(p)$, is considered to be a citizen of Ghana by default. This type of citizenship is based on some assumption and therefore cannot be logically queried beyond the assumption.

$\forall \mathrm{x}$ child $(\mathrm{x}) \rightarrow \exists \mathrm{p}, \operatorname{parent}(\mathrm{p}, \mathrm{x}) \wedge \operatorname{age}(\mathrm{x})<8 \wedge$ found $(\mathrm{x}, \operatorname{in}(\mathrm{gh})) \wedge \neg \operatorname{known}(\mathrm{p}) \rightarrow \operatorname{by} \operatorname{Birht}(\operatorname{Ctz}(\mathrm{x}$, $\mathrm{gh})$ )

The composition of some aspects of the law makes it challenging to process, especially for proofing complete logical deductions. While some aspects present open-ended statements, others are defined with limited logical provision.

Thus far, all the logical theorems provided in this study specifies or defines the various type of criteria for a person to obtain citizenship of Ghana. Each level of definition is uniquely defined by time stamps that determine the conditions that apply at the specified times. We will like to emphasise that, each stage of the model defined by each section of the Act presents sufficient premises for a person to be citizen of Ghana by birth.

Some of the interesting issues that are found in this discussion brings to bare other meanings presented by the statements of the pieces of law through formalism, which is quite different from the intention of the framing of the law, and reveal different semantics from the composition of the text made in their literal use. The analysis done by this paper affirms the importance of words and their meaning in legal statements which have always been debated in legal discourse in order to ascertain the implication of statements in decision-making processes.

\section{CONCLUSIONS}

Researchers in computer science, specifically in AI, have provided some tools to deal with the semantic problems in legal language, and are still generally seeking to provide improved versions of tools that exist, as well as new ones that can present legal language in crisp logical form that avoids confusion in the semantics of legal texts, as well as tools that can perform legal reasoning 
International Journal on Natural Language Computing (IJNLC) Vol.7, No.5, October 2018

in legal argumentation for precision in decision- making [31]. All of these converge to the fact that "...it is a necessary condition for a judicial condition to be legally justified that it coheres with some part of the established law" [32]; established law as a knowledge base to legal processes and systems, and coherence to the law as system of deductive reasoning for decisionmaking, which as yet remains a challenge, because there is no single robust logical system that can deal with this difficulty entirely[33].

In this paper, we explored the possibility of having an entire established law as a logic theorem, a form that generally revealed unintended or elusive semantic errors in natural expressions of the text, and as well preserve a sound reasoning mechanism through the text. We chose to formalise the Citizenship Act of Ghana which is a piece of law that presents technical and complex interconnected facts, thought processes and various kinds of deductive reasoning in its application. By this formalism, we have been able to semantically analyse the difference in the logical sequences of words in their natural use in the Citizenship Act and establish logical correctness in some aspects of the Act. Some of the interesting aspects in this formalism showed that, the use of the material implication and the exclusive or inclusive use of disjunctions have been particularly found in some cases not reflecting the logic intentions of the Act. The logic models also presents the text of the Act in a form that removes or minimizes ambiguities and establishes clarity for comprehensibility, and can as well serve as a deductive logic tool for the augmentation of decision-making in legal systems.

\section{ACKNOWLEDGEMENTS}

We are grateful to the library department of the Supreme Court of Ghana for supporting us with legal material and helping us understand some aspects of the Citizenship laws of Ghana.

\section{REFERENCES}

[1] T. Endicott (2016) "Law and Language" The Stanford Encyclopedia of Philosophy, accessed 5th October 2018, from <http://plato.stanford.edu/archives/sum2016/entries/law-language/>

[2] J. Dickson (2010) "Interpretation and Coherence in Legal Reasoning" The

Stanford Encyclopedia of Philosophy, accessed 5th October 2018, from $<$ http://plato.stanford.edu/archives/sum2014/entries/legal-reas-interpret/>

[3] Aristotle (1955) “On Sophistical Refutations” Loch Classical Library, Cambridge, Mass., Harvard University Press, accessed 5th October 2018, from

<http://www.hup.harvard.edu/catalog.php?isbn=9780674994416>

[4] D. N. Walton (1995) “A Pragmatic Theory Of Fallacy” University of Alabama Press.

[5] I. Witczak-Plisiecka (2007) "Language, law and speech acts: Pragmatic meaning in English legal texts” Łódź: WyŜszaSzkołaStudiówMiędzynarodowych w Łodzi.

[6] B. H. Sandra (1984) "The discourse of court interpretations: Practice of the law, witness and the interpreter", John Benjamins Publishing Company.

[7] J. P. Butt, and C. Richard (2006) "Modern legal drafting: A guide to using clearer language" New York: Cambridge University Press.

[8] A.B. Garner (2002) "The elements of legal style” New York: Oxford University Press.

[9] M. P. Tiersma (1999) "Legal language” Chicago: The University of Chicago Press.

[10] M. Asprey (2010) “ Plain Language for Lawyers,Federation Press.

[11] T. N. Hwee and Z. John (1997) “Corpus-Based Approaches to Semantic Interpretation in Natural Language Processing” The American Association for Artificial Intelligence Magazine, Vol. 18, No. 4.

[12] R. S. Trehan (2014) “An "Unfortunate Bit of Legal Jargon”; Prosecutorial Vouching Applied to Cooperating witness” Columbia Law Review Association Inc, Vol. 114, No. 4, pp997-1032. 
International Journal on Natural Language Computing (IJNLC) Vol.7, No.5, October 2018

[13] F. Michael and S. Fiona (2013) "Law and Language” Oxford University Press, Vol 15.

[14] A. Wagner and S. Cacciaguidi-Fahy (2006) "Legal Language and the search for Clarity: Practice and tools",Peter Langi.

[15] C. William (2006) "Fuzziness in Legal English: what shall we do with 'shall'?," Peter Lang.

[16] T. Bell (2018) "what is Natural Language Processing? The Business benefits of NLP Explained" CIO from IDG,accessed 5th October 2018,from<https://www.cio.com/article/3258837/artificialintelligence/what-is-natural-language-processing-the-business-benefits-of-nlp-explained.html>

[17] R. Mihalcea, H. Liu and H. Lieberman (2006) "NLP (Natural Language Processing) for NLP (Natural Language Programming)" in Gelbukh A. (eds) Computational Linguistics and Intelligent Text Processing. CICLing 2006. Lecture Notes in Computer Science, Vol. 3878. Springer, Berlin, Heidelberg.

[18] Grau, Harrock, Motik, Parsia, Patel-Schneider and Sattler (2008) "OWL2: The Next Step for OWL" University of Oxford, United Kingdom.

[19] A. Horn (1951) "On sentences which are true of direct union of algebras" Journal of Symbolic Logic, vol. 16, No. 1, pp14-21.

[20] P. B. Andrews (2002) “An Introduction to Mathematical Logic and Type Theory: To Truth Through Proof'Kluwer Academic Publishers, Springer.

[21] P. K. Pandya, (2005) "Monadic Second-Order Logic; Automata and Practice" University of Trento, TIFR, Mumbai, India, pp10-24.

[22] N. Bidoit and R. Hull (1989) "Minimalism, justification and non-monotonicity in deductive databases" Journal of Computer and System Sciences, Vol. 38, pp 290-325.

[23] B. Verheij, J. Hage, and A. R. Lodder (1997) "Logical tools for legal argument: a practical assessment in the domain of tort" Dissertation UniversiteitMaastricht, accessed 7th August 2018, from <http://pub.maastrichtuniversity.nl/d2a53c49-d176-41a8-a5c1-8e9234c62021>

[24] L. O. Kelso, (1946)“Does the law need a technological revolution?”Rocky Mountain Law Review, Vol. 18, pp378-392.

[25] N. Love and M. Genesereth (2005) “Computational Law”. ICAIL '05, ACM, 1-59593-081, Bologna, Italy, June 6-11, 2005.

[26] M. K. Anjali and P.A. Babu (2014) "Ambiguities in Natural Language Processing" International Journal of Innovative Research in Computer and Communication Engineering. Vol. 2, No. 5.

[27] G. Sator (19194) “A Formal model of Legal Argumentation” International Journal of Jurisprudence and Philosophy of Law.

[28] Wikipedia (2018) "Ghanaian Nationality Law", accessed 14th June 2018, from $<$ https://en.wikipedia.org/wiki/Ghanaian_nationality_law>

[29] United Nations High Commissioner for Refugees (UNHCR) (2016). Terms of Reference: Study on Statelessness in Ghana, Accra, Ghana

[30] UN High Commissioner for Refugees (UNHCR), UNHCR\& IOM, Nationality, Migration and Statelessness in West Africa (2015), accessed 22nd August 2018, from $<$ http://www.refworld.org/docid/55b886154.html>

[31] L. Al-Abdulkarim, K. Atkinson and T. J. M. Bench-Capon (2016) "A methodology for designing systems to reason with legal cases using Abstract Dialectical Frameworks" Artificial Intelligence and Law, Vol. 24, No. 1,pp1-49.

[32] B. B. Levenbook (1984) "The Role of Coherence in Legal Reasoning” Law andPhilosophy, Vol. 13, pp355-74.

[33] A. Gibson, G. Rowe and C. Reed (2007) "A Computational Approach to Identifying Formal Fallacy". Paper presented at Working Notes of the 7th Workshop on Computational Models of Natural Argument, CMNA 2007, pp26-30. 
International Journal on Natural Language Computing (IJNLC) Vol.7, No.5, October 2018

\section{AUTHORS}

Callistus Ireneous Nakpih is a lecturer at the St. John Bosco's College of Education in Ghana. He has functioned as head of some academic departments in the College of which the Quality Assurance Department is the latest. He is currently playing a national role in the development and integration of ICT policies into education in Ghana, as well as in the development of a new curriculum for pre-tertiary education in Ghana. As a researcher, he is interested in Artificial Intelligences especially in Natural Language Processing and is willing to explore in research not only to add to knowledge but to also advance the Computational development in Ghana.

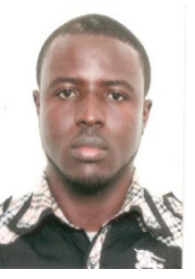

